\title{
Physical and verbal/emotional abuse of schoolchildren, Lebanon, 2009
}

\author{
C. El Bcheraoui, ${ }^{1}$ H. Kouriye ${ }^{7}$ and S.M. Adib ${ }^{7}$
}

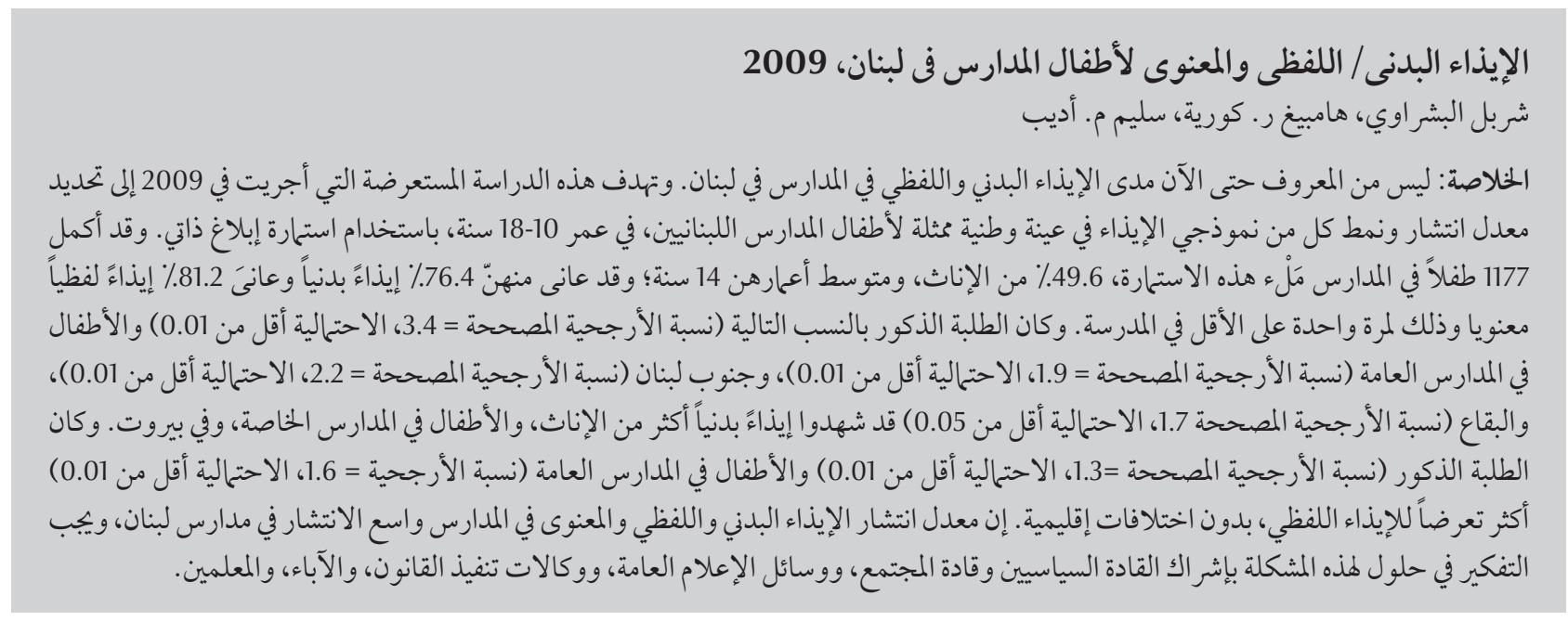

ABSTRACT The extent of physical and verbal/emotional abuse in schools in Lebanon is currently unknown. This cross-sectional study aimed to determine the prevalence and patterns of both forms of abuse among a nationally representative sample of Lebanese schoolchildren, aged 10-18 years, using a self-reported questionnaire. A total of 1177 schoolchildren, $49.6 \%$ females, median age 14 years, completed the survey; $76.4 \%$ and $81.2 \%$ of these had experienced physical and verbal/emotional abuse respectively at least once at school. Male students [adjusted odd ratio $(\mathrm{AOR})=3.4, P<0.01$, children in public schools $(\mathrm{AOR}=1.9, P<0.01)$ and in South Lebanon $(\mathrm{AOR}=2.2, P$ $<0.01$ ) and Bekaa ( $A O R=1.7, P<0.05$ ) regions were more likely to have experienced physical abuse than females, children from private schools and from Beirut. Male students $(A O R=1.3, P<0.01)$ and children in public schools $(\mathrm{AOR}=1.6, P<0.01)$ were also more likely to experience verbal abuse, with no regional differences. The prevalence of physical and verbal/emotional abuse in schools in Lebanon is high and solutions should be sought to correct the problem engaging political and social leaders, the mass media, law enforcement agencies, parents and educators.

\section{Violence physique et psychologique/verbale sur des élèves au Liban en 2009}

RÉSUMÉ L'importance de la violence physique et psychologique/verbale dans les écoles au Liban n'est pas connue. La présente étude transversale visait à déterminer la prévalence et les caractéristiques des deux formes de violence dans un échantillon d'élèves libanais âgés de 10 à 18 ans représentatifs au niveau national, à l'aide d'un questionnaire direct. Au total, 1177 élèves, dont 49,6 \% de filles, âgés en moyenne de 14 ans, ont rempli le questionnaire ; 76,4 \% et 81,2 \% d'entre eux avaient été exposés à la violence physique et psychologique/verbale respectivement au moins une fois à l'école. Les élèves de sexe masculin (OR ajusté $=3,4 ; P<0,01$ ), les élèves des écoles publiques (OR ajusté $=1,9 ; P<0,01$ ), du sud du Liban (OR ajusté $=2,2 ; P<0,01$ ), et de la vallée de Bekaa (OR ajusté $=1,7 ; P<0,05$ ), étaient plus à risque d'avoir été exposés à la violence physique que les élèves de sexe féminin, les enfants des écoles privés et de Beyrouth. Les garçons (OR ajusté $=1,3 ; P<0,01$ ) et les élèves des écoles publiques (OR ajusté $=1,6 ; P<0,01)$ étaient aussi plus à risque d'exposition à la violence verbale, sans différence entre les régions. La prévalence de la violence physique et psychologique/verbale chez les élèves au Liban est élevée et des solutions doivent être recherchées pour corriger le problème dont la responsabilité doit être partagée entre les dirigeants politiques et sociaux, les médias, les forces de l'ordre, les parents et les éducateurs. 


\section{Introduction}

Child abuse, defined as "physical injury, emotional abuse, sexual abuse or nonaccidental injuries or trauma inflicted on a child by another person", is an act of commission, an active act of maltreatment of children [1], which can take place in several settings: at home, at school, in the streets, in the workplace. The vulnerability of children to abuse, the multiplicity of ways through which abuse is expressed, and its numerous serious potential consequences render it an important public health issue [2].

Schools have an important role in protecting children from violence. Adults who oversee and work in educational settings have a duty to provide a safe environment that supports and promotes children's dignity and development. However, for centuries, children were abused in schools under the excuse of corporal "discipline". Abuse at school affects not only children's mental health and self-esteem, but also their desire to go to school and to acquire academic skills. Children abused at school tend to drop-out and become untrained, uneducated, unemployed citizens full of resentment and anger, and likely to engage in anti-social behaviours $[3,4]$. Sometimes, neither the child nor the perpetrator considers an abusive act as unusual or reprehensible. The victim feels guilty and ashamed, thinks that the violence was deserved and is embarrassed to report it [5].

Changing norms accompanied by stringent laws and regulations have consistently eroded the practice of corporal discipline since the second half of the 20th century. As physical abuse of schoolchildren by educators and other adults has declined, increasingly more interest has been directed towards emotional abuse and child-on-child physical or bullying. Bullying can be performed by individuals or gangs of children in or around school grounds [6]. Bullying is frequently associated with discrimination against students from poorer families or ethnically marginalized groups, or those with particular appearance, or a physical or mental disability [7]. Children who are victims of teachers' abuse are more likely to be bullied by fellow students, and conversely victims of bullying are also often subjected to maltreatment from school staff $[7]$.

Recent data from 37 countries showed that $86 \%$ of children aged $2-14$ years have ever experienced an episode of aggressive physical or emotional/ verbal discipline [8]. In almost all those countries, boys were slightly more likely to receive violent discipline than girls. In 32 countries, no significant differences in the use of violent discipline existed between households from the poorest $60 \%$ of the population and households from the richest 40\% [8].

In the Arab world, parents and educators may still be largely supportive of occasional use of physical punishment as a legitimate educational tool $[9,10]$. In a study in Alexandria, Egypt, $80 \%$ of boys and $60 \%$ of girls had been physically abused for the purpose of discipline [11]. In 2008, a teacher in Alexandria was convicted for murdering a student while "correcting" him [12]. Another study conducted in Egypt assessed the extent and the risk factors of both physical and verbal abuse committed by schoolchildren themselves [13]. It showed that more children were abused by other schoolchildren in public schools $(76 \%)$ than in private schools (62\%) [13]. In another study conducted in 6 public schools in one city in Tunisia, 37\% of the participating children reported being physically or verbally abused [14]. Finally, a study conducted on a large sample of teachers in summer camps and schoolchildren in Morocco showed that abuse still persisted in schools: $73 \%$ of teachers admitted abusing their students and $87 \%$ of participating children reported having been hit with a ruler or a stick [15].
The extent of physical and emotional abuse persisting in schools in Lebanon is currently unknown. The objectives of this national survey therefore was to:

- measure and describe for the first time the experience of physical and verbal/emotional abuse experienced by schoolchildren aged $11-18$ years old in school;

- assess differences in the abused children by gender, age, socioeconomic status, parental education and school location and type.

The aim of this survey was to inform policy-makers on the magnitude and determinants of a potential problem, and therefore to contribute evidence to upgrade relevant aspects of the Lebanese laws on physical and emotional abuse in schools.

\section{Methods}

\section{Study design and target population}

This national sample survey conducted in the spring of 2009 , targeted intermediate and secondary-school children (the equivalent of junior-high and high-school in the US system), aged 11-18 years old. The total population in that age bracket was estimated at 860,000 children of whom more than 95\% had ever been to school [16].

\section{Sample size}

To calculate the size for a random sample, we assumed a 50\% maximal lifetime prevalence of experiencing or witnessing abuse, based on the overall assessment of published data for the Arab world. This 50\% assumed prevalence ( $p$ ) was used in the basic formula for a simple random survey sample size:

$$
n=(\mathrm{Z} \alpha)^{2} \times \mathrm{p}(1-\mathrm{p}) / \delta^{2}
$$

Where $\mathrm{Za}$ for a type 1 error not exceeding 0.05 is 1.96 and $\delta$ is the 
tolerated sampling error, limited to $4 \%$. Under these conditions, a sample of 600 children would be required but, since a convenience non-random sampling approach was used, a design effect of 2 was allowed, which brought the sample size required to a minimum of 1200 .

\section{Sampling procedures}

Students were recruited through nongovernmental organizations (NGOs) participating in a network of "neighbourhood youth centres" supported by the Ministry of Social Affairs, from all mohafazat (administrative districts), in groups proportionate to the schoolchildren population in those mohafazat and proportionate to their distribution in age groups $11-14$ and $15-18$ years [16]. In each age group, the gender parity was observed. Ten per cent of the sample was selected from among Palestinian children from particular areas where Palestinian communities can be found. This proportion represents the "accepted" current proportion of the Palestinian population in Lebanon.

\section{Study instrument and administration procedures}

An Arabic version of a standardized questionnaire was obtained from the International Society for the Prevention of Child Abuse and Neglect (ISPCAN) [17]. This Arabic version had been translated and validated for previous use in Arab North African countries. It required minor modifications adapted to the Lebanese culture and local vocabulary, as suggested by the piloting process, conducted with 20 students from urban and rural areas. The questionnaire was designed to be self-completed under the supervision of trained field workers. Children affiliated with a neighbourhood centre present on the day when surveyors visited were divided in groups not exceeding 5 at a time in the same room to provide enough space for privacy.
The field worker explained the aim of the survey and showed the participants how to complete each group of questions. Field workers took some time to clarify what "ever experienced" and "never experienced" any type of abuse meant. They remained in the room until all the surveys were completed, and were allowed to briefly explain the items should any child request such explanations. If numbers required from one specific neighbourhood centre were not obtained on one visit, another visit was conducted on another day within the same week.

\section{Study variables}

The questionnaire included detailed sections concerning all types of abuse that might be experienced at school. The questionnaire included 19 questions on physical abuse and 12 on mental abuse. For each type of abuse ever admitted, students were asked who the perpetrators were: teachers and/or other students. For each sort of abuse, there were 4 levels of experience: many times in the past year, sometimes in the past year, happened but not in the past year, and never. These final 2 ordinal variables were considered as the outcomes of the analysis. Experience of all types of abuse was summed in a quantitative score, subsequently divided into 4 ordinal levels of experience around the distribution tertiles (after excluding those with score 0: "never" (score 0); "ever" (1-5), "sometimes" (6-10) and "many times" (>10).

The last section of the questionnaire explored the sociodemographic characteristics of the participants: age; sex; school system (public or private); family size; and socioeconomic status (SES) as indicated by the crowding index measured in number of persons per room in the household. This index had previously been validated as a good measure of SES in Lebanon [18]. Higher crowding is a sign of lower SES. This variable was subsequently divided into 2 categories: low-to-middle SES ( $\geq 1$ person/room] and middle-tohigh SES ( $<1$ person/room]. Parents' educational level was also recorded in 5 levels from "no education" to "college education". The education levels of both parents were added to create a summative "parental education index".

\section{Plan of analysis}

All national outcomes were weighted for the proportional representation of each region, and presented with their $95 \%$ confidence intervals (95\% CI). Variables associated with the outcomes in the bivariate analyses were included in a multivariate analysis to assess their adjusted effects. The significance of the multivariate linear coefficient for each independent variable was assessed using a chi-squared test for linearity. A $P$-value $\leq 0.05$ was considered statistically significant. All data were entered and analysed using SPSS, version 16.0.

\section{Ethical considerations}

Clearance was obtained from the Ethics Board of the Faculty of Medicine of Saint-Joseph University in Beirut. A letter was sent out to parents at least 3 days before the interviews presenting the aim of the study, and requesting them to sign a form if they did NOT approve of their child's participation in the study. The aim of the study was presented to the participating children.

\section{Results}

\section{Sociodemographic characteristics of the children}

The sociodemographic characteristics of surveyed children are shown in Table 1. The questionnaire was completed by 1177 children (98\% of the targeted sample size), with a median age of 14 years. The sex distribution and the regional distribution were almost equal. 


\begin{tabular}{|c|c|c|}
\hline Variable & No. (\%) & $\begin{array}{l}\text { Mean (SD); } \\
\text { Median [range] }\end{array}$ \\
\hline \multicolumn{3}{|l|}{ Sex } \\
\hline Male & $591(50.4)$ & \\
\hline Female & $581(49.6)$ & \\
\hline Age (years) & & $14.5(2.2) ; 14$ [10-18] \\
\hline \multicolumn{3}{|l|}{ Regions } \\
\hline Greater Beirut (city + suburbs) & $319(27.1)$ & \\
\hline Mount Lebanon & $205(17.4)$ & \\
\hline South Lebanon & $254(21.6)$ & \\
\hline North Lebanon & $245(20.8)$ & \\
\hline Bekaa & $154(13.1)$ & \\
\hline \multicolumn{3}{|l|}{ School system } \\
\hline Public & $629(53.9)$ & \\
\hline Private & $537(46.1)$ & \\
\hline Siblings & & $2.8(1.7) ; 3[0-15]$ \\
\hline 0 & $30(2.6)$ & \\
\hline 1 & $202(17.3)$ & \\
\hline 2 & $342(29.4)$ & \\
\hline 3 & $296(25.4)$ & \\
\hline 4 & $140(12.0)$ & \\
\hline$>4$ & $155(13.3)$ & \\
\hline Crowding index (persons/room) & & $1.5(1.2) ; 1.3[0.17-28.0]$ \\
\hline $\begin{array}{l}\text { Middle-high social status ( }<1 \text { person/ } \\
\text { room) }\end{array}$ & $385(32.7)$ & \\
\hline Middle-low social status & $792(67.3)$ & \\
\hline \multicolumn{3}{|l|}{ Mother's education } \\
\hline Rudimentary & $83(7.0)$ & \\
\hline Primary school & $257(21.8)$ & \\
\hline Intermediate (junior-high) school & $212(18.0)$ & \\
\hline Secondary (high) school & $297(25.2)$ & \\
\hline College & $200(17.0)$ & \\
\hline Unknown & $113(11.0)$ & \\
\hline \multicolumn{3}{|l|}{ Father's education } \\
\hline Rudimentary & $80(6.8)$ & \\
\hline Primary school & $268(22.8)$ & \\
\hline Intermediate (junior-high) school & $220(18.7)$ & \\
\hline Secondary (high) school & $231(19.6)$ & \\
\hline College & $221(18.8)$ & \\
\hline Unknown & 135 (13.3) & \\
\hline Parents' education score & & $4.5(2.0) ; 4.5[0-8]$ \\
\hline \multicolumn{3}{|l|}{ Mother's employment } \\
\hline Full-time & $145(12.3)$ & \\
\hline Part-time & $168(14.3)$ & \\
\hline Housewife & $864(73.4)$ & \\
\hline
\end{tabular}

$S D=$ standard deviation .

\section{Recall of physical abuse events at school}

More than half of the surveyed students (54.4\%) stated that they had never experienced abuse at school, whether physical or emotional, in the past year. However after responding to all the questions, only about $24 \%$ of the children could still be considered as never having experienced physical abuse at school in the past year, while about $7 \%$ had experienced it "often" in the past 12 months. The overall physical abuse score ranged from 0 to 57 , with a median score of 5; details are presented in Table 2.

Among those with any experience of physical abuse, the perpetrators were almost equally divided between teachers and/or other children. The most frequently mentioned act of physical abuse was getting hit with a ruler (43\% of the children) with various frequency levels. Some of the most egregious acts suggested to the children were rarely mentioned, such as having one's mouth washed with soap or pepper, burnt with cigarettes, doused with hot or cold water, tied by a rope or being choked as punishment.

\section{Recall of verbal or emotional abuse events at school}

Recall of verbal/emotional abuse was generally more frequent than that of physical violence, and student peers were more frequently cited as the perpetrators than teachers. About 19\% of the children denied ever having experienced emotional/verbal abuse in the past year, while almost $20 \%$ experienced it "often". The most frequently recalled act of verbal abuse was being deliberately insulted ( $51.7 \%$ ); in $65.2 \%$ of cases by other children only and in $16.1 \%$ by both teachers and schoolmates. The overall emotional abuse score ranged from 0 to 33, with a median value of 5 (Table 2). 


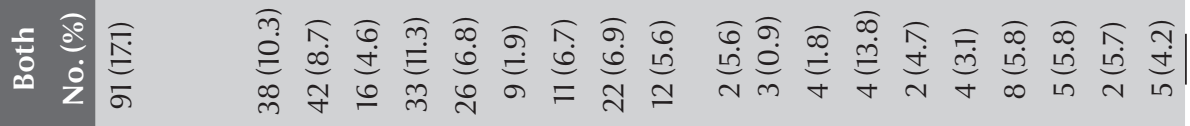

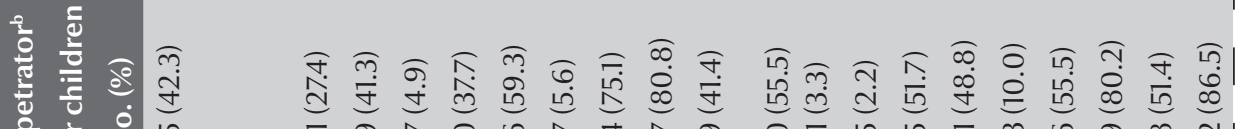

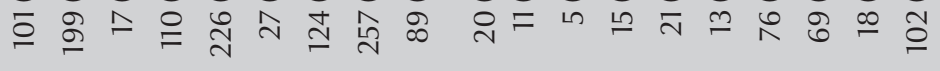

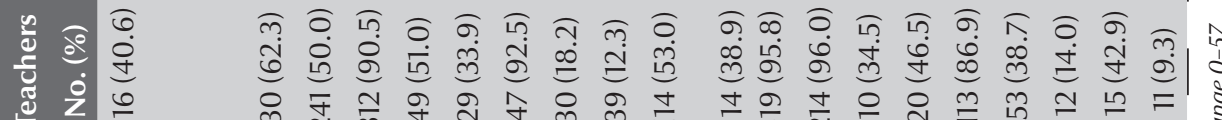

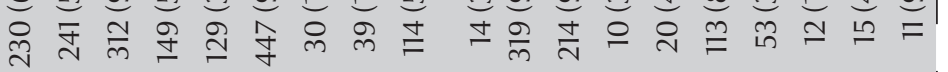

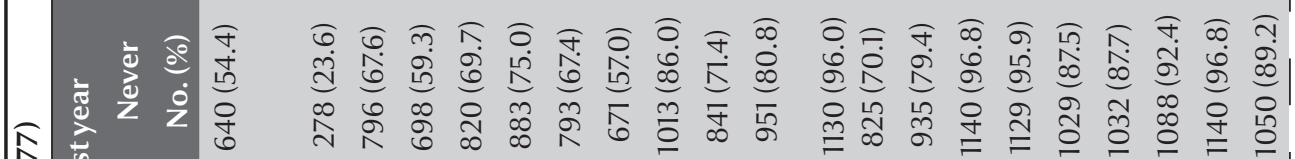

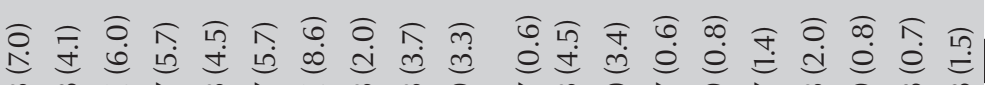

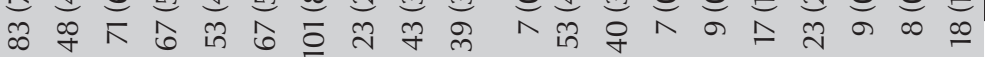

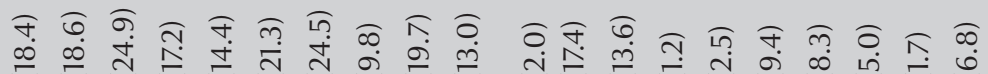

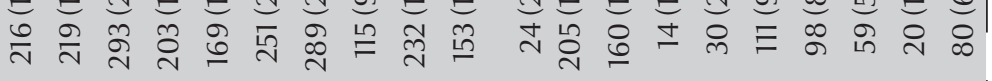

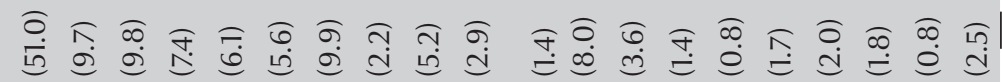

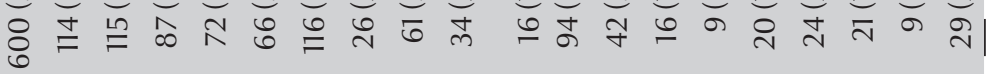




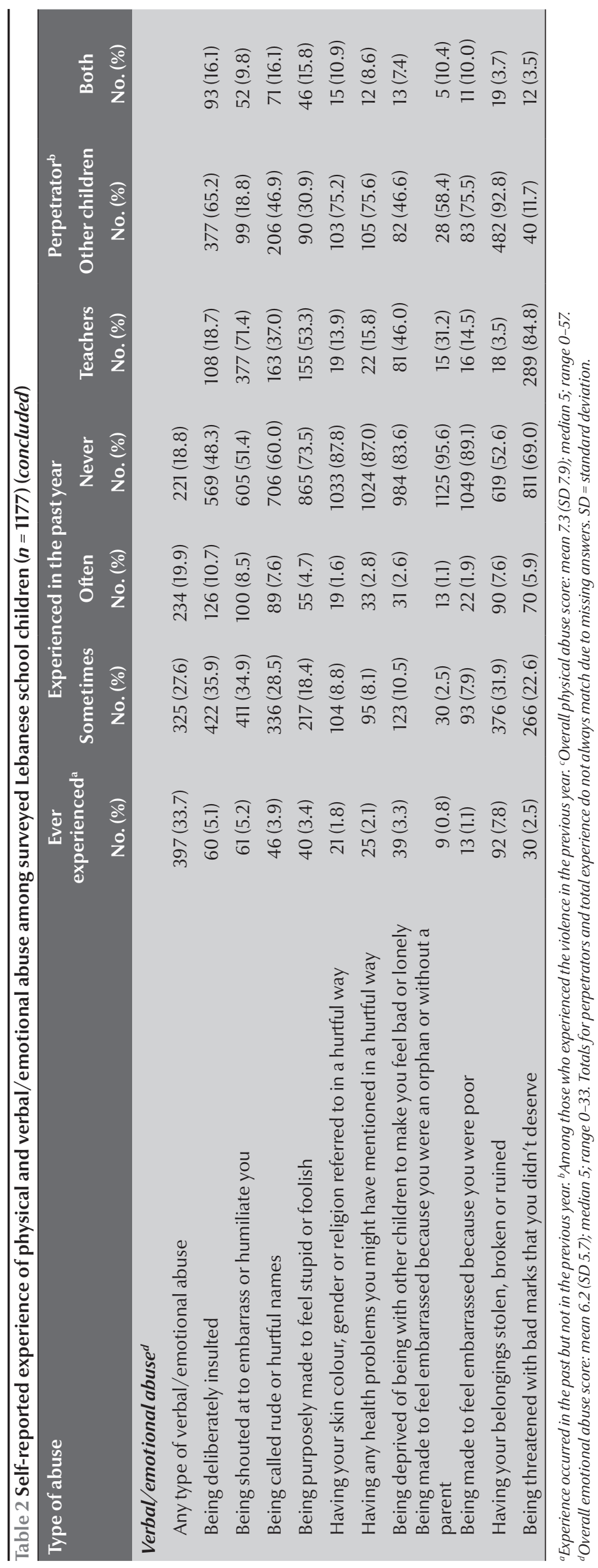

\section{Sociodemographic variables associated with physical abuse}

Table 3 shows the frequency of physical abuse according to the sociodemographic variables assessed and the results of the multivariate linear regression analysis. Males were almost twice as likely to report being sometimes or often abused (34\%) than females (17\%) in the past year. The intensity of recalled abuse decreased significantly with age. Abuse was more frequently reported by students of public schools. Those who had often experienced physical abuse came from relatively larger families (mean of 3 siblings), with lower socioeconomic status (mean crowding index of 1.8), and lower parental educational attainment (mean 3.7). South Lebanon had the highest frequency of students who had experienced abuse often (13.0\%), while Mount-Lebanon had the highest frequency of students who had never experienced physical abuse (27.8\%) (Table 3).

After adjustment in the multivariate linear regression analysis, male gender (3.4), older age (-0.6), public schooling (1.9), number of siblings (0.6) and lower parental education $(-0.3)$ remained statistically significantly associated with physical abuse. The multivariate model explained $42 \%$ of the variability in the experience of physical abuse among schoolchildren.

\section{Sociodemographic variables associated with verbal/emotional abuse}

Table 4 shows the frequency of verbal/emotional abuse according to the sociodemographic variables assessed and the results of the multivariate linear regression analysis. Male gender was significantly associated with experience of verbal/ emotional abuse, as was younger age. Verbal/ emotional abuse was more frequently reported by children in public than in private schools. Larger family size, lower parental education and lower socioeconomic status were also associated with emotional/verbal abuse. While levels of verbal abuse were slightly higher in South Lebanon and Bekaa, there were less regional differences with this type of abuse than with physical abuse.

In the multivariate regression analysis, younger age, male gender and public schooling remained significantly associated with suffering abuse, but region, family size, lower parental education and socioeconomic status did not. However, the model explained only $26 \%$ of the 


\begin{tabular}{|c|c|c|c|c|c|c|}
\hline \multirow[t]{4}{*}{ Variable } & \multicolumn{4}{|c|}{ Physical abuse } & \multirow{4}{*}{$\begin{array}{c}\text { Multivariate } \\
\text { linear regression } \\
\text { coefficient }\end{array}$} & \multirow[t]{4}{*}{$P$-value } \\
\hline & \multirow{3}{*}{$\begin{array}{c}\begin{array}{c}\text { Ever } \\
\text { experienced }\end{array} \\
\text { No. (\%) }\end{array}$} & \multicolumn{3}{|c|}{ Experienced in the past year } & & \\
\hline & & Never & Sometimes & Often & & \\
\hline & & No. (\%) & No. (\%) & No. $(\%)$ & & \\
\hline Total & $600(51.0)$ & $278(23.6)$ & $216(18.4)$ & $83(7.0)$ & & \\
\hline \multicolumn{7}{|l|}{ Sex } \\
\hline Male & $287(48.6)$ & $104(17.6)$ & $143(24.2)$ & $57(9.6)$ & 3.4 & $<0.001$ \\
\hline Female & $310(53.4)$ & $174(29.9)$ & $71(12.2)$ & $26(4.5)$ & Reference & \\
\hline \multicolumn{7}{|l|}{ School system } \\
\hline Public & $318(50.6)$ & $118(18.8)$ & $128(20.3)$ & $65(10.3)$ & 1.9 & $<0.001$ \\
\hline Private & $275(51.2)$ & $158(29.4)$ & $87(16.2)$ & $17(3.2)$ & Reference & \\
\hline Mother's employment & & & & & $\mathrm{NI}$ & \\
\hline Full-time & $78(53.8)$ & $35(24.1)$ & $23(15.9)$ & $9(6.2)$ & & \\
\hline Part-time & $89(53.0)$ & $37(22.0)$ & $31(18.5)$ & $11(6.5)$ & & \\
\hline \multirow[t]{2}{*}{ Housewife } & $410(49.7)$ & $198(23.8)$ & $156(18.9)$ & $63(7.6)$ & & \\
\hline & Mean (SD) & Mean (SD) & Mean (SD) & Mean (SD) & & \\
\hline Age (years) & $14.7(2.2)$ & $14.8(2.2)$ & $13.9(2.1)$ & $13.5(1.8)$ & -0.6 & $<0.001$ \\
\hline Siblings (no) & $2.5(1.1)$ & $2.3(1.1)$ & $2.7(1.1)$ & $3.0(1.0)$ & 0.6 & 0.005 \\
\hline $\begin{array}{l}\text { Crowding index } \\
\text { (person/room) }\end{array}$ & $1.7(0.5)$ & $1.6(0.5)$ & $1.7(0.5)$ & $1.8(0.4)$ & 0.5 & 0.07 \\
\hline $\begin{array}{l}\text { Parents'education } \\
\text { score }\end{array}$ & $5.0(2.0)$ & $5.0(2.0)$ & $4.0(2.2)$ & $3.7(1.5)$ & -0.3 & 0.005 \\
\hline Regional prevalence & $\%(95 \% \mathrm{Cl})$ & $\%(95 \% \mathrm{Cl})$ & $\%(95 \% \mathrm{Cl})$ & $\%(95 \% \mathrm{Cl})$ & & \\
\hline Greater Beirut & $50.2(44.7-55.7)$ & $25.1(20.3-29.9)$ & 19.7 (15.3-24.1) & $5.0(2.6-7.4)$ & Reference & \\
\hline Mount Lebanon & $56.6(49.8-63.3)$ & $27.8(21.7-33.9)$ & $12.2(7.7-16.7)$ & $3.4(0.9-5.9)$ & -0.5 & 0.5 \\
\hline North Lebanon & $56.3(50.2-62.4)$ & $22.9(17.7-28.1)$ & $15.9(11.4-20.4)$ & $4.9(2.2-7.5)$ & -0.4 & 0.5 \\
\hline South Lebanon & $44.9(38.7-51.1)$ & $25.6(20.1-31.1)$ & $16.5(11.8-21.1)$ & $13.0(8.8-17.2)$ & 2.2 & 0.001 \\
\hline Bekaa & $46.8(38.9-54.7)$ & $13.0(7.7-18.3)$ & $30.5(23.2-37.8)$ & $9.7(5.0-14.4)$ & 1.7 & 0.03 \\
\hline
\end{tabular}

${ }^{a}$ Experience occurred in the past but not in the previous year.

$\mathrm{NI}=$ not included in the multivariate analysis because it was not significantly associated with the outcome in univariate analysis.

$S D=$ standard deviation; $C l=$ confidence interval .

variability in the experience of verbal/ emotional abuse.

\section{Physical and verbal/ emotional abuse correlation}

The scores of physical and verbal/ emotional abuse were highly correlated (Pearson coefficient 0.62) suggesting a clustering of victimization in some children.

\section{Discussion}

This first national survey showed that the experience of physical and verbal/ emotional abuse is relatively common in schools in Lebanon. The sample was drawn essentially from neighbourhood youth centres more likely to be frequented by low to medium SES children from public schools. This selection bias may have resulted in an over-estimation of the national experience of abuse especially in subsamples from the more affluent areas of Beirut and Mount-Lebanon, but less so from other areas. However, if the external validity of the estimated prevalence figures can be disputed, there is no reason to believe that the internal validity of the findings, regarding determinants of abuse experience is affected.
There were important differences in reported lifetime experiences of physical abuse and verbal/ emotional abuse. While $76.4 \%$ of the schoolchildren reported any lifetime experience of physical abuse, verbal/ emotional abuse was even more common (81.2\%). According to the children, physical abuse was most often perpetrated by adults, teachers or administrative staff, while verbal abuse was most often perpetrated by other children. Verbal abuse perpetrated by children against each other might sometimes be similar to gang bullying. This survey however did not document the possible existence and extent 


\begin{tabular}{|c|c|c|c|c|c|c|}
\hline \multirow[t]{4}{*}{ Variable } & \multicolumn{4}{|c|}{ Verbal/emotional abuse } & \multirow{4}{*}{$\begin{array}{l}\text { Multivariate } \\
\text { linear } \\
\text { regression } \\
\text { coefficient }\end{array}$} & \multirow[t]{4}{*}{ P-value } \\
\hline & \multirow{3}{*}{$\begin{array}{c}\begin{array}{c}\text { Ever } \\
\text { experienced }^{\mathrm{a}}\end{array} \\
\text { No. (\%) }\end{array}$} & \multicolumn{3}{|c|}{ Experienced in the past year } & & \\
\hline & & Never & Sometimes & Often & & \\
\hline & & No. (\%) & No. (\%) & No. (\%) & & \\
\hline Total & $397(33.7)$ & $221(18.8)$ & $325(27.6)$ & $234(19.9)$ & & \\
\hline \multicolumn{7}{|l|}{ Sex } \\
\hline Male & $205(34.7)$ & $82(13.9)$ & $170(28.8)$ & $134(22.6)$ & 1.3 & $<0.001$ \\
\hline Female & $191(32.9)$ & 139 (23.9) & $151(26.0)$ & $100(17.2)$ & Reference & \\
\hline \multicolumn{7}{|l|}{ School system } \\
\hline Public & $186(29.6)$ & $107(17.0)$ & $178(28.3)$ & $158(25.1)$ & 1.6 & $<0.001$ \\
\hline Private & $207(38.5)$ & $113(21.0)$ & $142(26.4)$ & $75(14.0)$ & & \\
\hline \multicolumn{7}{|l|}{ Mother's employment } \\
\hline Full-time & $51(35.2)$ & $24(16.6)$ & $43(29.7)$ & $27(18.6)$ & & \\
\hline Part-time & $53(31.5)$ & $29(17.3)$ & $49(29.2)$ & $37(22.0)$ & & \\
\hline \multirow[t]{2}{*}{ Housewife } & $282(34.1)$ & $159(19.2)$ & $220(26.6)$ & $166(20.1)$ & $\mathrm{NI}$ & \\
\hline & Mean (SD) & Mean (SD) & Mean (SD) & Mean (SD) & & \\
\hline Age (years) & $14.6(2.2)$ & $14.5(2.3)$ & $14.6(2.2)$ & $14.1(2.1)$ & -0.2 & 0.007 \\
\hline Siblings (no.) & $2.4(1.1)$ & $2.4(1.1)$ & $2.6(1.1)$ & $2.7(1.1)$ & 0.2 & 0.2 \\
\hline $\begin{array}{l}\text { Crowding index } \\
\text { (persons/room) }\end{array}$ & $1.7(0.5)$ & $1.6(0.5)$ & $1.7(0.5)$ & $1.7(0.5)$ & 0.1 & 0.7 \\
\hline $\begin{array}{l}\text { Parents'education } \\
\text { score }\end{array}$ & $4.7(2.0)$ & $4.8(2.0)$ & $4.5(2.0)$ & $4.0(2.0)$ & -0.2 & 0.6 \\
\hline Regional prevalence & $\%(95 \% \mathrm{Cl})$ & $\%(95 \% \mathrm{Cl})$ & $\%(95 \% \mathrm{Cl})$ & $\%(95 \% \mathrm{Cl})$ & & \\
\hline Greater Beirut & $32.0(26.8-37.1)$ & $16.0(12.0-22.0)$ & $30.1(25.1-35.1)$ & $21.9(17.4-26.4)$ & Reference & \\
\hline Mount Lebanon & $34.1(27.6-40.6)$ & $22.0(16.3-27.7)$ & $24.2(18.6-30.3)$ & $19.5(14.0-24.9)$ & -0.4 & 0.5 \\
\hline North Lebanon & $38.0(32.0-44.0)$ & $21.2(16.1-26.2)$ & $24.9(19.6-30.2)$ & $15.9(11.4-20.4)$ & -0.9 & 0.07 \\
\hline South Lebanon & $31.9(26.0-37.7)$ & $21.3(16.2-26.2)$ & $24.0(18.6-29.3)$ & $22.8(17.5-28.0)$ & 0.7 & 0.15 \\
\hline Bekaa & $33.1(25.6-40.5)$ & $12.3(7.1-17.5)$ & $37.0(25.7-40.5)$ & $17.5(11.5-23.5)$ & -0.1 & 0.9 \\
\hline
\end{tabular}

a Experience occurred in the past but not in the previous year.

$\mathrm{NI}=$ not included in the multivariate analysis because it was not significantly associated with the outcome in univariate analysis.

$N S=$ not significantly associated with the outcome.

$S D=$ standard deviation; $C l=$ confidence interval .

of bullying in Lebanese schools, which is an important issue worthy to be investigated using more appropriate qualitative research tools.

The sociodemographic characteristics of any given child were likely to determine his/her status as a victim of physical abuse, but less as a victim of verbal abuse. More children in the public school system reported various degrees of abuse of all types than children in the private system. Children in rural areas such as South Lebanon and Bekaa were at more likely to experience physical abuse than those in more urbanized areas. Abusers seemed to target preferentially students from the less educated, bigger and more socially disadvantaged families. Living in rural areas remained a risk factor for physical abuse even when socioeconomic status and school system were controlled for, suggesting that this variable acts through factors beyond the victim-victimizer dyad. However, regional differences disappeared with verbal/emotional abuse, which was equally widespread in all regions, at higher levels than those of physical abuse.

Some of the personal characteristics which seemed to render children more likely targets for physical abuse by teachers in Lebanon are similar to those reported in a similar survey conducted in another Arab country, Yemen [10]. Risk factors common to the 2 surveys included: living in rural areas, male gender, low parental education and large family size. The higher risk for abuse in boys compared to girls was also found in a national survey in the United States [19], suggesting a universal trend not affected by varying cultural norms.

Reporting of abuse decreased with age. This finding may be explained in a variety of ways. Younger children live 
episodes of abuse in a more vivid way than older ones, and therefore remember them more frequently than older children. Those episodes per se must not have reached sufficiently serious levels to cause longer-term memories. Indeed, children rarely reported experiencing the more severe types of abuse listed in the questionnaire. Children initially tended to assert that they had not experienced abuse when asked generally but when specific types of abuse were explored one by one, it became clear that may more had experienced what would be considered abuse. Older students were less likely to report being slapped around or emotionally abused, and it may be that memories of earlier abuse are not reinforced and end up fading away.

Physical abuse experienced by schoolchildren in school is more specifically a school-based phenomenon than verbal/emotional abuse since the children reported being victimized mostly by adults, teachers or staff members. Therefore this problem has to be tackled at the school level. Rules and regulations forbidding physical discipline are clearly more largely advertised and enforced in private schools and/or urban areas. Ministerial memorandums, which are sent out periodically if complaints are received to remind all of the stipulations of the laws or regulations which allegedly have been ignored, are clearly not sufficient to stop the use of physical abuse by teachers and staff in public schools everywhere and/or in all schools in rural areas. The protection of children in those areas, and especially those from socially vulnerable backgrounds, should be ensured through active spot inspections of schools. On those visits, inspectors from the Ministry of Education should insist on meeting students and parents, using procedures to reassure and protect from future retribution those willing to report abuse. The possibility of reporting abuse through a confidential hotline could also be considered.

Children who engage in verbal abuse against each other very likely reflect a reality which exists outside schools, one in which parents and other community members are role models. That this type of abuse is more widespread than physical abuse, and that urban/rural differences are less strongly associated with its occurrence, indicate that the reality of verbal abuse is a problem of national dimension. The larger context leading to increasing verbal/emotional abuse among children in schools is further indicated by the fact that children's specific demographic and familial factors were less predictive of verbal than of physical victimization. We would argue that the erosion of social respect and public good manners cannot but seep through inside inter-parental, parent-child, inter-siblings and child-child interactions: poor manners received at home are easily carried to school. While some corrective measures may be enacted through curricular activities, the real response to the reality of verbal/ emotional abuse among schoolchildren should come mostly from outside schools. Our study showed a high rate of both physical and verbal/emotional abuse in school which suggest the urgent need for corrective measures to address this highly prevalent problem, which should be the shared responsibility of political and social leaders, the mass media, law enforcement agencies and parents as well as educators.

\section{Acknowledgement}

This work was supported by Save the Children, Sweden in a research agreement for which no grant number was provided.

The cooperation of the staff of the Ministry of Education and the Ministry of Social Affairs is acknowledged with gratitude.

\section{References}

1. Ramos-Gomez F, Rothman D, Blain S. Knowledge and attitudes among California dental care providers regarding child abuse and neglect. Journal of the American Dental Association (1939), 1998, 129:340-348.

2. World Health Organization. Resolution WHA 49-25. Prevention of violence: public health priority. Forty-ninth World Health Assembly, Geneva, 1996.

3. Harrison PA, Fulkerson JA, Beebe TJ. Multiple substance use among adolescent physical and sexual abuse victims. Child Abuse \& Neglect, 1997, 21:529-539.

4. Finzi R et al. Depressive symptoms and suicidality in physically abused children. American Journal of Orthopsychiatry, 2001, 71:98-107.

5. Deblinger E, Runyon MK. Understanding and treating feelings of shame in children who have experienced maltreatment. Child Maltreatment, 2005, 10:364-376.

6. Srabstein J et al. Prevention of public health risks linked to bullying: a need for a whole community approach. Inter- national Journal of Adolescent Medicine and Health, 2008, 20:185-199.

7. Khoury-Kassabri M. The relationship between staff maltreatment of students and bully-victim group membership. Child Abuse \& Neglect, 2009, 33:914-923.

8. UNICEF. Childinfo. Monitoring of the situation of children and women (2010). (http://www.childinfo.org/, accessed 18 July 2012)

9. Al-Mahroos FT. Child abuse and neglect in the Arab Peninsula. Saudi Medical Journal, 2007, 28:241-248.

10. Alyahri A, Goodman R. Harsh corporal punishment of Yemeni children: occurrence, type and associations. Child Abuse \& Neglect, 2008, 32:766-773.

11. Youssef RM, Attia MS, Kamel MI. Children experiencing violence. II: Prevalence and determinants of corporal punishment in schools. Child Abuse \& Neglect, 1998, 22:975-985.

12. Abu Shal N, Al-Sharkawi N. Teacher kills student in Alex because he does not do "homework". Al-Masry Al-Youm 28 October 2008. 
13. Ez-Elarab HS et al. Prevalence and risk factors of violence among elementary school children in Cairo. Journal of the Egyptian Public Health Association, 2007, 82:127-146.

14. Ben Abdelaziz A et al. Les jeunes victimes de violence en milieu scolaire urbain à Sousse (Tunisie) [Victims of violence in urban secondary schools in Sousse (Tunisia)]. Santé (Montrouge, France), 2003, 13:165-170.

15. Belhaj I. New report discusses child abuse in Morocco. Magha rebia, 7 May 2007.

16. Statistical bulletin, 2008. Beirut, Lebanon, Ministry Of Public Health; 2009.

17. ISPCAN Child Abuse Screening Tools (ICAST). Questionnaire and Guides available for UN Study on Violence against Chil- dren (http://www.ispcan.org/?page=ICAST\&hhSearchTerms= questionnaire, accessed 22 September 2012).

18. Melki IS et al.National Collaborative Perinatal Neonatal Network (NCPNN). Household crowding index: a correlate of socioeconomic status and inter-pregnancy spacing in an urban setting. Journal of Epidemiology and Community Health, 2004, 58:476-480.

19. Thompson MP, Kingree JB, Desai S. Gender differences in longterm health consequences of physical abuse of children: data from a nationally representative survey. American Journal of Public Health, 2004, 94:599-604.

\section{Corrections}

W.M. Ali, K.F. Al Habib, A. Hersi, N. Asaad, K. Sulaiman, A. Al-Shiek-Ali and J. Al Suwaidi. In-hospital complications and 1-year outcome of acute coronary syndrome in patients with hypertension: findings from the 2nd Gulf Registry of Acute Cardiac Events. Eastern Mediterranean Health Journal, 2012, 18(9):902-910. On page 907, the last sentence of the first paragraph should read: When adjusted for sex and comorbidities, age was an independent predictor for in-hospital mortality in hypertensive (OR $=1.04,95 \% \mathrm{CI}: 1.03-1.06, P<$ $0.001)$ (Table 6) and non-hypertensive patients ( $\mathrm{OR}=1.06,95 \% \mathrm{CI}: 1.05-1.07, P<0.001)$.

P. Chikvaidze, H.H. Madi and R.K. Mahaini Mapping family planning policy and programme best practices in the WHO Eastern Mediterranean Region: a step towards coordinated scale-up. Eastern Mediterranean Health Journal, 2012, 18(9):911-919. On page 911, the authors' affiliations should read: ${ }^{1}$ Women's Reproductive Health; ${ }^{2}$ Health Protection and Promotion Division; ${ }^{3}$ Family and Community Health Unit, World Health Organization, Regional Office for the Eastern Mediterranean, Cairo, Egypt (Correspondence to P. Chikvaidze:chikvaidzep@emro.who.int). 